\title{
The Relationship between Parental Socioeconomic Status and Mortality in Premature Infants in Hospitals
}

\author{
Seyed Mojtaba Hosseini ${ }^{1,}$, , Khalil Ali Mohammadzadeh ${ }^{1}$, Zeinab Mohammadi Ebli ${ }^{1}$ \\ ${ }^{1}$ Department of Health Services Management, Tehran North Branch, Islamic Azad University, Tehran, Iran \\ *Corresponding Author: Seyed Mojtaba Hosseini, MD, PhD in Health Services Management, Department of Health Services Management, \\ Tehran North Branch, Islamic Azad University, Tehran, Iran. Email: hosseinisch@yahoo.com
}

\begin{abstract}
Introduction: Measuring the patient mortality rate is the most important indicator for the evaluation of healthcare capabilities in intensive care units in hospitals and health systems. This study aims to investigate the impact of the socio economic status of households on premature infant mortality in hospitals affiliated to the Tehran University of Medical Sciences.

Methods: This descriptive and analytic study was conducted in hospitals, having neonatal intensive care units (NICU), affiliated to the Tehran University of Medical Sciences in the spring of 2013. Using the census sampling method, 114 premature infants constituted the sample of the current study. Data was gathered using a questionnaire and analyzed using chi square and Fisher methods.

Results: The results of the study showed that there is a significant statistical relationship $(\mathrm{P}<0.05)$ between the variables of maternal educational levels, employment status of mothers, birth spacing, history of previous neonatal death, parental smoking history and mothers' self-assessments of economic status of household with premature infant mortality in neonatal intensive care units (NICU).

Conclusion: According to the results of this study and the relationship between the mentioned variables, increasing health awareness among parents and their education level can be considered as a significant factor in reducing infant mortality and also focusing on promoting healthy behavior can have a desirable impact on the reduction of premature infant mortality.
\end{abstract}

Keywords: Socioeconomic Factors, Infant Mortality, Intensive Care Units, Neonatal, Hospitals

Article History: Received: 27 Feb. 2015; Accepted: 6 May. 2015; Online Published: 24 Aug. 2015

Cite this article as: Hosseini SM, Mohammadzadeh KA, Mohammadi Ebli Z. The relationship between parental socioeconomic status and mortality in premature infants in hospitals. Int J Travel Med Glob Health. 2015;3(3):119-22.

\section{Introduction}

Nowadays, despite advances in medical science, premature infant birth is still a major problem within our society. In addition to economic and psychological problems in families, premature birth causes the loss of financial resources and human capital as well. In this regard, a study conducted in Boston, USA, in 1997, concluded that negative behavioral characteristics among premature infants are more than mature infants $[1,2]$.

In the recent decades, infant mortality rates have decreased significantly in developed and developing countries. Among the factors affecting infants' mortality and their hospital admissions in specialized units, the socioeconomic status of parents, especially mothers, has a significant impact. Previous studies showed a statistically significant correlation between social exclusion of parents and infant mortality [3].

Diseases associated with infants and mortality caused by them impose the financial and emotional burden on their families. Also they impose substantial direct costs, due to the use of advanced technologies and specialized units, and indirect costs, due to parental absenteeism from work to receive needed services, on the health system and the whole society. Infant mortality has a significant impact on the average life expectancy of the population and slight improvement in the infant mortality and morbidity rates has a relatively greater impact on the increase in life expectancy. Also, the reduction of infant mortality and disorders during infancy causes the flow of resources to other needy sectors and finally leads to the increase in health and welfare of the community. Two-thirds of deaths in the first year of life could be due to preterm delivery [4].

This complication in infants causes an increase in the length of hospital stay, increased hospital costs and imposes additional costs on patients, their families and the health system. It may also cause serious physical and psychological effects on the baby years later [5]. Preterm delivery of has a multi factorial etiology and in most cases the cause is unknown; however, among many unknown causes, the socio economic status has been identified as one of the causes [6].

Given that prenatal care services are provided free of charge to those in need of these services and a portion of annual health care costs is dedicated to these services in Iran, the birth of healthy infants is a matter of great importance. If the pregnancy does not lead to the birth and infant survival, it causes the loss of financial and human capitals. Premature born babies need inpatient care in a neonatal intensive care unit which imposes heavy costs on their parents and families as well as the healthcare system. The current study aims to investigate the relationship between variables determining the socio economic status of parents, such as educational levels, income and employment status, and mortality in premature infants hospitalized in neonatal intensive care units in hospitals affiliated to the Tehran University of Medical Sciences.

\section{Methods}

This cross-sectional descriptive and analytic study was designed and conducted to investigate the relationship between parental socioeconomic status and mortality in premature infants in hospitals affiliated to the Tehran University of Medical Sciences in the spring of 2013. In this study, using the census sampling method, all premature infants born in hospitals affiliated to the Tehran University of Medical Sciences in the spring of 2013 and hospitalized in neonatal intensive care units were selected as the sample of the study. Totally, 119 premature infants were identified and among them, 5 cases did not participate in the study and 114 cases constituted the sample of the current study. Data 
regarding the socio economic status of parents of hospitalized premature infants was gathered using a questionnaire. The questionnaire included 21 questions in three categories about variables of fathers, mothers and the whole household and also one question, at the beginning of the questionnaire, about the consequence of the hospitalization for the infant (infant discharge or death). Choices of the questions in the questionnaire were nominal and to do so, numerical rating and Likert scales were used. In this study, the economic status was measured using questions about the household income and the employment status of mothers. The social status of parents participating in this study was measured using questions about maternal age, parental education, parental smoking status, household size, family history of previous neonatal death, birth order and birth spacing. To collect and complete information, medical records of infants were reviewed and in some cases, parents of premature infants were contacted. In the next step, the collected data were analyzed by using the chi square and the Fisher Exact statistical methods.

\section{Results}

The results of the study showed that the mortality rate of premature infants hospitalized in neonatal intensive care units in hospitals affiliated to the Tehran University of Medical Sciences was 7.8 percent. In this study, there is a significant statistical relationship between the employment status of mothers and premature infant mortality $(\mathrm{P}<0.05)$. This means the rate of mortality among infants of employed mothers was relatively less than housewife mothers (Table 1).

In this study, the mortality of premature infants among mothers with a history of previous neonatal death was more than others $(\mathrm{P}<0.05)$ (Table 2$)$.

Also, the results of the investigation on smoking status showed that the rate of mortality among infants of fathers who smoke was relatively higher $(\mathrm{P}<0.05)$ (Table 3$)$.

Table 1. The relationship between the employment status of mothers and premature infant mortality

\begin{tabular}{lccc}
\hline $\begin{array}{l}\text { Employment Status } \\
\text { of Mothers }\end{array}$ & \multicolumn{2}{c}{ Hospitalization Outcome } & \multirow{2}{*}{$\begin{array}{c}\text { Total } \\
\text { N }(\%)\end{array}$} \\
\cline { 2 - 3 } & $\begin{array}{c}\text { Discharge } \\
\mathbf{N}(\%)\end{array}$ & $\begin{array}{c}\text { Death } \\
\mathbf{N}(\%)\end{array}$ & $\mathbf{8}(100)$ \\
\hline Housekeeper & $83(91.2)$ & $8(8.8)$ & $91(100)$ \\
Employee & $22(95.6)$ & $1(4.4)$ & $23(100)$ \\
Total & $105(92.2)$ & $9(7.8)$ & $114(100)$ \\
\hline
\end{tabular}

Table 2. The relationship between mortality of premature infants among mothers and premature infant mortality

\begin{tabular}{|c|c|c|c|}
\hline \multirow{2}{*}{$\begin{array}{l}\text { Mortality of Premature } \\
\text { Infants among Mothers }\end{array}$} & \multicolumn{2}{|c|}{ Hospitalization Outcome } & \multirow{2}{*}{$\begin{array}{l}\text { Total } \\
\mathbf{N}(\%)\end{array}$} \\
\hline & $\begin{array}{c}\text { Discharge } \\
\mathbf{N}(\%)\end{array}$ & $\begin{array}{l}\text { Death } \\
\mathbf{N}(\%)\end{array}$ & \\
\hline Yes & $35(89.8)$ & $4(10.2)$ & $39(100)$ \\
\hline No & $70(93.3)$ & $5(6.7)$ & $75(100)$ \\
\hline Total & $105(92.2)$ & $9(7.8)$ & $114(100)$ \\
\hline
\end{tabular}

Table 3. The relationship between history of smoking fathers and premature infant mortality

\begin{tabular}{lccc}
\hline \multirow{2}{*}{$\begin{array}{c}\text { History of } \\
\text { Smoking Fathers }\end{array}$} & \multicolumn{2}{c}{ Hospitalization Outcome } & \multirow{2}{*}{\begin{tabular}{c} 
Total N \\
\cline { 2 - 3 }$(\boldsymbol{\%})$
\end{tabular}} \\
\cline { 2 - 3 } Housekeeper & $61(91)$ & $6(9)$ & $67(100)$ \\
Employee & $44(93.6)$ & $3(6.4)$ & $47(100)$ \\
Total & $105(92.2)$ & $9(7.8)$ & $114(100)$ \\
\hline
\end{tabular}

The results of the study showed that there is a significant statistical relationship between the education level of mothers and infants mortality $(\mathrm{P}<0.05)$. This means when the educational levels of mothers increases, the rate of premature infant mortality decreases (Table 4).

Table 4. The relationship between education level of mothers and premature infant mortality

\begin{tabular}{lccc}
\multicolumn{3}{c}{$\begin{array}{c}c \\
\text { Education Level of } \\
\text { Mothers }\end{array}$} & \multicolumn{2}{c}{$\begin{array}{c}\text { Hospitalization } \\
\text { Outcome }\end{array}$} & $\begin{array}{c}\text { Total } \\
\text { N }(\%)\end{array}$ \\
\cline { 2 - 3 } & $\begin{array}{c}\text { Discharge } \\
\text { N }(\%)\end{array}$ & $\begin{array}{c}\text { Death } \\
\text { N }(\%)\end{array}$ & \\
\hline Illiterate & $2(66.6)$ & $1(33.3)$ & $3(100)$ \\
Primary & $7(87.5)$ & $1(12.5)$ & $8(100)$ \\
High School & $17(85)$ & $3(15)$ & $20(100)$ \\
Diploma & $53(92.9)$ & $4(7.1)$ & $57(100)$ \\
College & $8(100)$ & $0(0)$ & $8(100)$ \\
B.A & $15(100)$ & $0(0)$ & $15(100)$ \\
M.Sc., M.A \& Ph.D. & $3(100)$ & $0(0)$ & $3(100)$ \\
Total & $105(92.2)$ & $9(7.8)$ & 114 \\
\hline
\end{tabular}

Table 5. The relationship between mothers' self-assessments of economic status and premature infant mortality

\begin{tabular}{|lccc}
\hline \multirow{2}{*}{$\begin{array}{c}\text { Mothers' Self-Assessments } \\
\text { of Economic Status }\end{array}$} & \multicolumn{2}{c}{$\begin{array}{c}\text { Hospitalization } \\
\text { Outcome }\end{array}$} & \multirow{2}{*}{$\begin{array}{c}\text { Total } \\
\text { N }\end{array}$} \\
\cline { 2 - 3 } & $\begin{array}{c}\text { Discharge } \\
\text { N (\%) }\end{array}$ & $\begin{array}{c}\text { Death } \\
\text { N }(\%)\end{array}$ & \\
\hline Deprived area & $8(72.7)$ & $3(27.3)$ & $11(100)$ \\
Relatively deprived area & $24(85.7)$ & $4(14.3)$ & $28(100)$ \\
Average & $57(96.6)$ & $2(3.4)$ & $59(100)$ \\
Affluent area & $14(100)$ & $0(0)$ & $14(100)$ \\
Relatively Affluent area & $2(100)$ & $0(0)$ & $2(100)$ \\
Total & $105(92.2)$ & $9(7.8)$ & $114(100)$ \\
\hline
\end{tabular}

The results of the investigation on mothers' selfassessments of economic status of households showed that the infant mortality rate was higher among mothers assessed as more deprived $(\mathrm{P}<0.05)$ (Table 5).

\section{Discussion}

Given that prematurity is one of the most common causes of infant mortality, the identification of risk factors and underlying causes of mortality in this population may help to identify premature infants who are at the risk of death, to shift health care services and ultimately to reduce the chance of death [7]. However, most of the conducted studies on infant mortality have considered the neonatal period as a whole. Also, the issue of mortality among premature infants, which are in turn the most common target group for infant mortality, has received less attention.

The results of the study showed that the mortality rate of premature infants hospitalized in neonatal intensive care units in hospitals affiliated to the Tehran University of Medical Sciences was 7.8 percent.

Poor Arian et al. conducted a study to investigate the rate and causes for premature infant mortality in hospitals in Shiraz and the rate was found to be about 18.2 percent. The rate found in the current study is lower than that of the study conducted by Poor Arian et al. One of the reasons for this difference may be significant advances in facilities and equipment in neonatal intensive care units for premature infants in the recent years [8].

Studies show there is a close relationship between the prematurity and cultural and socio economic status of households. Problems resulting from low socioeconomic levels including nutritional deficiency, anemia, maternal disease, inadequate prenatal care, drug addiction and other obstetric complications can affect the futurity of an infant.

A study conducted by Dibben C. et al. showed that there is 
a significant statistical relationship between social class, household income, mother's age at birth and living in deprived areas with premature infant birth and death [9].

The investigation of the relationship between the variables of maternal educational levels and premature infant mortality in intensive care units in this study showed that there is a significant statistical relationship between increases in maternal educational levels and premature infant mortality, i.e. the increase in maternal educational levels positively impacts mothers' health behavior and deeply affects the reduction in premature infant mortality through different ways. For example it increases the awareness of the importance of prenatal care, having optimal interval between births, chooses the right age to get pregnant, opts for a proper diet plan during pregnancy and so on. A study titled "The impact of social inequalities on infant mortality in northern Belgium", conducted by Devlieger et al., showed that parental educational levels as well as professional career skills of parents have a significant impact on the reduction in mortality [10].

The results of the current study regarding the impact of the increase in maternal education levels on the reduction in infant mortality are consistent with those of a study, titled "an epidemiologic study of infant mortality and stillbirths and associated factors in the province of Kurdistan", conducted by Nadim et al. These findings are also consistent with those of a study, titled "the investigation of the rate and causes for premature infant mortality in hospitals in Shiraz ", conducted by Pourazin et al. This means the increase in mothers' knowledge and awareness of risk factors of premature births, young mothers in particular, and the importance of prenatal care to prevent premature birth can play an effective role in reducing the incidence of premature births $[8,11]$.

In this study, a significant statistical relationship was observed between the variables of maternal employment status and premature infant mortality in intensive care units. Thus, the rate of infant mortality among employed mothers was lower than housewife ones. This can be explained by the linkage between maternal education and employment, so that employed mothers are more likely to have higher education or income; this matter, in turn, is a significant factor in the reduction of premature infant mortality and a small percentage of mothers inevitably seeks employment (they do not want to be housewife). Various studies indicate that the prevalence of premature infant birth in poorer areas with lower income households is higher than in wealthy areas and affluent households $[12,13,14]$.

The results of this study showed that there is a significant statistical relationship between the variables of the history of previous neonatal death and infant mortality in intensive care units. The history of previous neonatal death can increase the risk of infant mortality. A study, titled "factors affecting stillbirths and infant death in rural areas are covered by health houses in the provinces of Khorasan and West Azerbaijan", conducted by Allahyari, also showed that the mother's history of stillbirth can increase the risk of infant death and, in particular, stillbirth [15].

In this study, a significant statistical relationship was observed between the variables of parental smoking history and infant mortality in intensive care units. There was a higher rate of mortality in infants with parents with a smoking history. Smoking not only raises the risk of infant mortality, but also increases future disorders at older ages.

\section{Conclusion}

The present study aimed at investigating the impact of the socio economic status of households on premature infant mortality in hospitals affiliated to Tehran University of Medical Sciences. The results of this study show that in addition to genetic variables, prenatal care and socio economic factors of households may significantly affect infant mortality and, in particular, premature infants. Thus, macro policy making in the country should lead towards increasing educational levels and also awareness among population. Smoking is another factor contributing to increased infant mortality. Informing the population on harms from smoking and macro and long term planning in order to culture building for reducing smoking in long term can greatly help to grow and develop healthy and empowered human resources in the future. The findings of the study showed that the increased household income and welfare level may play a key role in reducing infant mortality. General policies for employment and increased welfare levels in the society may be considered as a solution for reducing the birth of premature infants and consequently their death.

\section{Acknowledgments}

This study was a part of a M.A dissertation that was approved by the Islamic Azad University, Tehran North Branch.

\section{Authors' Contributions}

SMH and KAM were involved in the study design. ZME was involved in result interpretation. All authors confirmed the final draft before submission.

\section{Financial Disclosure}

The authors declared no financial disclosure.

\section{Funding/Support}

Not declared.

\section{References}

1. Chapieski ML, Evankovich KD. Behavioral effects of prematurity. American J Prenatal. 1997;14(2):75-8.

2. Mehryar AH. Population, development and pregnancy health, Boshra publishing and promoting, Tehran: third ed,1379, 19-20. Persian]

3. Jenkins J, McCall E, Gardner E, Casson K, Dolk H. Socioeconomic inequalities in neonatal intensive care admission rates. Arch Dis Child Fetal Neonatal Ed 2009;94:F423-8.

4. Henderson ZT, Power ML, Berghella V, Lackritz EM, Schulkin J. Attitudes and practices regarding use of progesterone to prevent preterm births. Am J Perinatol. 2009;26(7):529-36.

5. da Fonseca EB, Bittar RE, Carvalho MH, Zugaib M. Prophylactic administration of progesterone by vaginal suppository to reduce the incidence of spontaneous preterm birth in women at increased risk: a randomized placebocontrolled double-blind study. Am J Obstet Gynecol. 2003;188(2):419-24.

6. Gabbe SG. Definition, detection, and management of gestational diabetes. Obstet Gynecol. 1986;67(1):121-5.

7. Lawn JE, Cousens S, Zupan J. 4 million neonatal deaths: When? Where? Why? Lancet. 2005;365:891-900.

8. Pourazin S, Vafadar A, Zare Z. The incidence of premature birth, complications, and outcomes in Shiraz University of Medical Sciences. J Iran University Med Sci. 2010;9(28):19-26. Persian

9. Dibben C, Sigala M, Macfarlane A. Area deprivation, individual factors and low birth weight in England: is there evidence of an "area effect"'?. J Epidemiol Community Health. 2006;60:1053-9.

10. Devlieger H, Martens G, Bekaert A. Social inequalities in perinatal and infant mortality in the northern region of Belgium (the Flanders). Eur J Public Health. 2005;15(1):15-19.

11. Nadim A. An epidemiologic study of stillbirths and infant mortality and associated factors in the Kurdistan province. J Kurdistan 
University Med Sci. 2000;4(13):10-19. Persian

12. Walton E. Residential segregation and birth weight among racial and ethnic minorities in the United States. J Health Soc Behav. 2009;50:427-42.

13. Colen CG, Geronimus AT, Bound J, James SA. Maternal upward socioeconomic mobility and black-white disparities in infant birthweight. Am J Public Health. 2006;96:2032-9.
14. Olson ME, Diekema D, Elliott BA, Renier CM. Impact of income and income inequality on infant health outcomes in the United States. Pediatrics. 2010;126:1165-73.

15. Alahyari M. Factors affecting mortality and stillbirths in rural areas are covered by health houses in the Province of West Azerbaijan. [M.Sc Thesis]. Tehran: School of Health, Tehran University of Medical Sciences, 1999. Persian 